\title{
Una maqueta en una mano: hacia la búsqueda de lo esencial
}

\section{Resumen}

La contemporaneidad tiene que empezar a eliminar lo superfluo. Trabajar la maqueta de pequeño tamaño es un ejercicio que obliga al arquitecto a sintetizar y a buscar la esencia del proyecto. Contener una idea en una mano lleva implícito un triple esfuerzo: la búsqueda de la síntesis; la búsqueda de la materia y la búsqueda de la razón. Este ejercicio desarrollará tres encuentros: el encuentro con lo imprescindible de una idea; el encuentro con un soporte físico que la construya y el encuentro con una lógica organizadora; tres encuentros que tendrán su confluencia en la maqueta de arquitectura. Este recurso ha sido una referencia continua no solo de los arquitectos, sino también de los artesanos.

El presente artículo parte de la reflexión teórica que supone mirar a la arquitectura como el ejercicio manual de un artesano. La relación directa entre la mano y la maqueta, así como el proceso de fabricación de esta, serán caracteres identitarios de una arquitectura propia. La relación de estos elementos evidenciará la necesidad de una reflexión teórica profunda sobre las herramientas contemporáneas del arquitecto. Huyendo de grandes excentricidades y de discursos complejos alejados de la sociedad, el artículo analizará algunos discursos y arquitecturas teniendo siempre presente cómo estos muestran que una buena idea y una buena maqueta siempre caben en una mano.

\author{
Pablo Manuel Millán-Millán \\ Doctor arquitecto \\ Profesor Escuela de Arquitectura y \\ Diseño \\ Pontificia Universidad Católica de \\ Valparaíso \\ Valparaíso, Chile \\ Escuela Técnica Superior de \\ Arquitectura \\ Universidad de Sevilla \\ Sevilla, España \\ Correo electrónico: pmillan1@us.es \\ ๑ orcid.org/0000-0001-5343-6957 \\ Google Scholar
}

Recibido: Octubre 25 de 2017 Aprobado: Julio 24 de 2018

Palabras clave:

Síntesis, maqueta, artesano, materia, razón, proyecto. 


\section{A scale model in one hand: towards the search for the essential}

\begin{abstract}
Contemporaneity must begin to eliminate the superfluous. Working the scale model is an exercise that forces the architect to synthesize and seek the essence of the project. Containing an idea in one hand implicitly involves a triple effort: the search for synthesis, the search for matter, and the search for reason. This exercise will develop three encounters: the encounter with the essential of an idea; the encounter with a physical support that builds it; and the encounter with an organizing logic. These three encounters will have their confluence in the architecture scale model. This resource has been a continuous reference, not only of the architects, but also of the artisans.

This article is based on the theoretical reflection that involves looking at architecture as the manual exercise of the artisan. The direct relationship between the hand and the scale model, as well as its production will be the identifying characteristics of a typical architecture. The relationship of these elements will evidence the need for a deep theoretical reflection on the contemporary tools of the architect. Fleeing from great eccentricities and complex discourses away from society, the article will analyze some discourses and architectures always bearing in mind how they show that a good idea and a good scale model always fit in one hand.
\end{abstract}

Key words:

Synthesis, model, craftsman, matter, reason, project. 


\section{Introducción}

Tanto el artesano como el arquitecto necesitan desarrollar relaciones específicas entre el pensamiento y la creación, entre la idea y la ejecución, la acción y la materia, el aprendizaje y la técnica, la identidad propia y la obra sobre la que esta se proyecta; en definitiva, entre la idea y el ejercicio de proyectación. Este trabajo dota al creador de extensiones propias a uno mismo, sus propias obras. Podríamos hacer un recorrido y observar los paralelismos proyectuales entre artesanos/artistas/arquitectos y el desarrollo de su trayectoria profesional. Este ejercicio mostraría el carácter confluyente de la labor del artesano y del arquitecto. Un análisis como este es el que nos lleva a asumir la indivisibilidad de las disciplinas de uno y otro. El presente artículo sintetiza el trabajo docente llevado a cabo con un grupo de alumnos y presentado en las $\checkmark$ Jornadas sobre Innovación docente en Arquitectura, en la Escuela Técnica Superior de Arquitectura de la Universidad de Sevilla (España) entre el 16 y 17 de noviembre de 2017.

Al igual que son muchas las características comunes, el desarrollo de diversas teorías de pensamiento ha ido generando a lo largo de la historia de la arquitectura otras cosmovisiones divergentes. Elementos como la historia, el lugar, los materiales o simplemente la técnica empleada, han sido algunos de los argumentos esgrimidos por La Modernidad para trazar un nuevo camino en la teoría arquitectónica. Hoy, bajo el dominio de una posmodernidad permisiva con numerosos resquicios interpretativos del mundo de la arquitectura, han surgido nuevas voces que demandan una vuelta a lo local; en el sentido topográfico y político de la palabra, reivindicando su propio pensamiento e historia. 
Parece como si la humanidad, al enfocar en masa a una cultura de consumo básico, se hubiera detenido también en masa en un nivel infracultural. Así llegamos al problema crucial con el que se encuentran las naciones que están saliendo del subdesarrollo. A fin de llegar a la ruta que conduce a la modernización, ¿es necesario desechar el viejo pasado cultura que ha sido la razón de ser de una nación? He aquí la paradoja. Por un lado tienen que arraigar en el suelo de su pasado, forjar un espíritu nacional y desplegar esta reivindicación espiritual y cultural ante la personalidad colonialista. Pero a fin de tomar parte en la civilización moderna, es necesario al mismo tiempo tomar parte en la racionalidad científica, técnica y política, algo que muy a menudo requiere el puro y simple abandono de todo un pasado cultural. Es un hecho: no toda cultura puede soportar y absorber el choque de la moderna civilización. Existe esta paradoja: cómo llegar a ser moderno y regresar a las fuentes, cómo revivir una antigua y dormida civilización y tomar parte en la civilización universal. (Ricoeur, 1965, p. 276-277)

No cabe duda de que la aparición de las vanguardias en la sociedad, y concretamente en la arquitectura, jugaron un papel fundamental en la compresión de un nuevo orden que favorecía la libertad y el progreso del hombre. Pero es igualmente cierto que los extremos de posicionamiento llevados por diversas formaciones culturales como el futurismo, dadaísmo, entre otros, abrieron una dura crítica contra cualquier elemento que pudiera recordar a discursos pretéritos. Estos procesos de ruptura acabaron a la vez con las vinculaciones con el lugar y con su historia. El discurso del artesano no pasaría por un proceso paralelo y, aun sirviendo a nuevas artes y nuevos requerimientos, siempre se mantendría vinculado a las técnicas locales. Su rechazo origina un discurso propio en el nuevo panorama arquitectónico:

¡Nos hallamos sobre el último promontorio de los siglos!... ¿Por qué deberíamos mirar a nuestras espaldas, si queremos echar abajo las misteriosas puertas de lo Imposible? El Tiempo y el Espacio murieron Ayer. Nosotros ya vivimos en lo absoluto, pues hemos creado ya la eterna velocidad omnipresente. (Marinetti, 2015)

Asimismo, este espíritu quedará recogido en el programa de la Bauhaus en el que Gropius (1919) dirá: 
¡Arquitectos, escultores, pintores, todos hemos de volver al artesanado! No existe un 'arte profesional'. No hay ninguna diferencia sustancial entre el artista y el artesano. El artista es un artesano de nivel superior [...]. ¡Así pues, formemos una nueva corporación de artesanos, pero sin aquella arrogancia que pretendía erigir un muro infranqueable entre artesanos y artistas! Aportemos todos nuestra voluntad, nuestra inventiva, nuestra creatividad en la nueva actividad constructora del futuro, que será todo en una sola forma: arquitectura, escultura y pintura, y que millares de artesanos elevarán hacia el cielo como símbolo cristalino de una nueva fe que está surgiendo. El fin último, aunque remoto, de la Bauhaus es la obra de arte unitaria - la gran arquitectura-, en la que no existe una línea de demarcación entre el arte monumental y el arte decorativo. (p. 40)

A pesar de estas posturas intelectuales en pro de un funcionalismo basado en la máquina y en la tecnología del momento habrá numerosos arquitectos que, asumiendo los principios del Movimiento Moderno, quieran seguir otra lógica. Estamos hablando del regionalismo crítico, del cual Kenneth Frampton dará buen detalle describiéndolo como un movimiento de retaguardia. Hablamos de un grupo de arquitectos que usarán las historia, el lugar, la técnica... bajo una doble acción: desaprender lo aprendido bajo las directrices de la contemporaneidad e insertarlas en un nuevo discurso local.

Tomando prestado de este regionalismo crítico la vinculación con el lugar como clara diferencia con el Movimiento Moderno, la lógica del artesano se definirá en el proceso de ideación del proyecto arquitectónico. Por ejemplo, y como subraya Juhani Pallasmaa, Renzo Piano - aun siendo uno de los arquitectos high-tech más sofisticados de la actualidad- ha conservado un proceso artesanal en la elaboración del proyecto, en el dibujo, en la experimentación y en la ejecución de la obra. Así, el artesano y el arquitecto desarrollan una misma lógica cuando recorren un mismo camino teórico, comparten el ejercicio de proyectar cuando se acercan desde una misma cosmovisión y vehiculan caracteres identitarios cuando para ambos el proyecto es una idea que proporciona la base para comenzar a trabajar. 


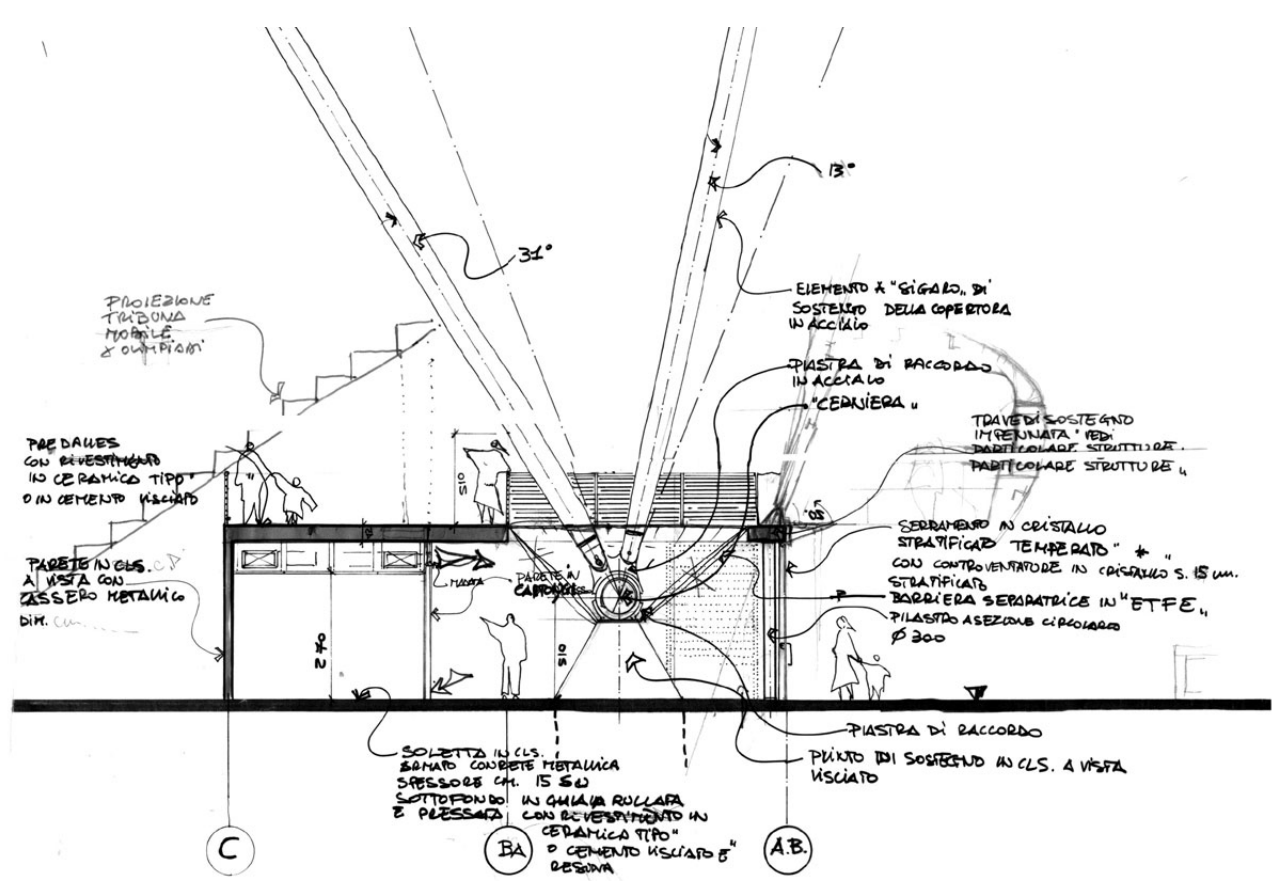




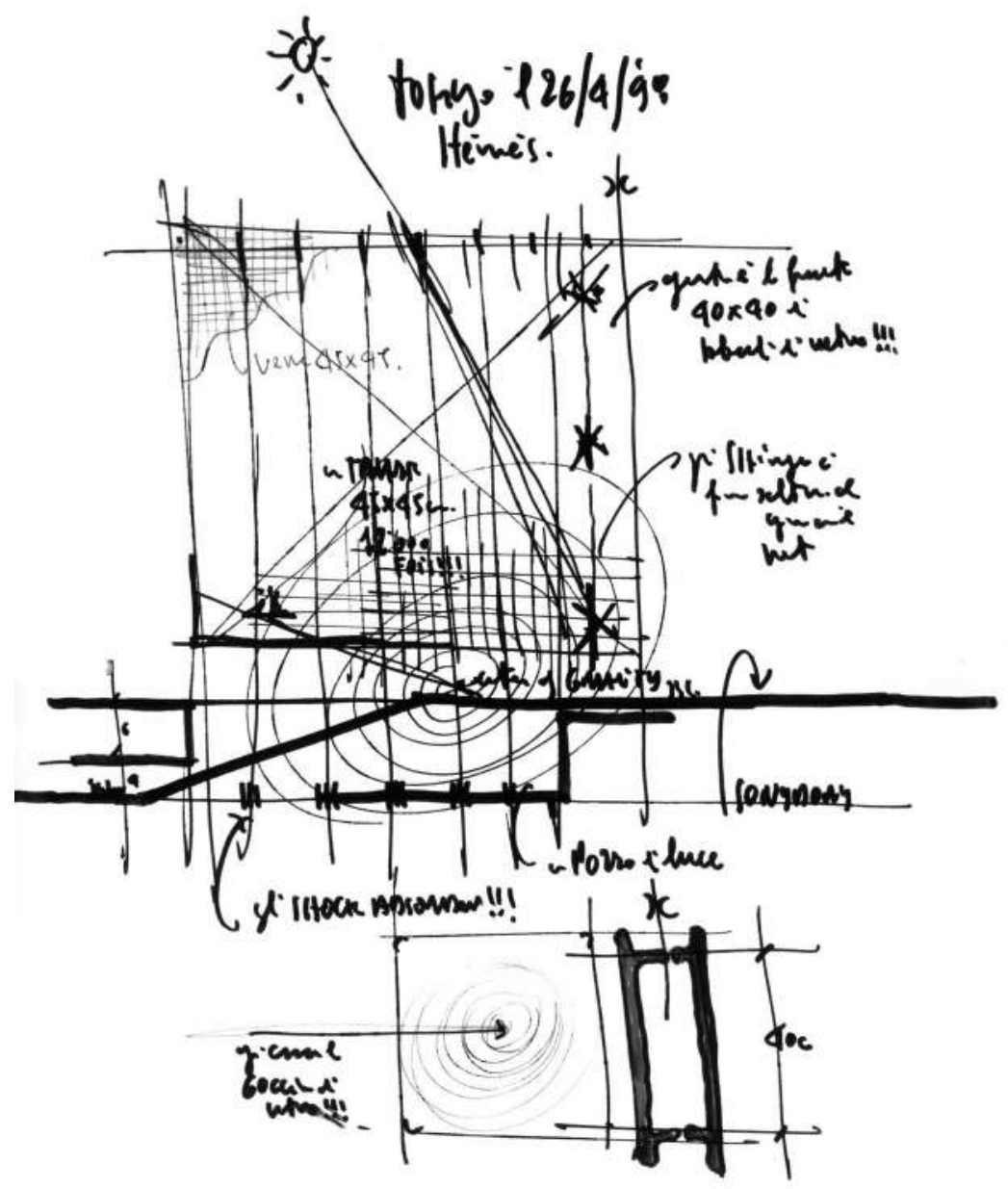

Figuras 1, 2. Dibujos de Renzo Piano. Fuente: www.plataformaarquitectura.cl. 
La complejidad que encierra la naturaleza de los espacios contemporáneos favorecida por la mezcla de lenguajes, recursos o materialidades ha ido generando un entumecimiento sensitivo que, como dijera Louis I. Kahn (2003), comienza a demandar una depuración espacial y material. "Allí, el ojo no logra retener ningún objeto que sea más pequeño que un coche. La insensibilidad sensorial encuentra su culminación en la arquitectura intrusiva y exhibicionista del edificio" (Pallasmaa, 2015, p. 155). Con esta afirmación tan contundente Pallasmaa hace referencia a la pérdida de sensaciones detectadas dentro del Centro Pompidou, quizá por el valor negativo del exceso. Esta complejidad que en sí misma contiene la riqueza de lo plural (Morin, 2006) puede caer en la búsqueda de lo complejo como objeto de origen y meta. La sociedad contemporánea, compleja por el entramado de discursos, redes, relaciones y tautologías, se materializa en un soporte físico; huella de un pasado que interacciona con el presente: la ciudad. Esta es el resultado de la suma de numerosas partes, es el elemento cambiante que se adapta como buen soporte a una serie de actividades propias de su contemporaneidad (Capel, 2002). Para poder adentrarnos en ella habrá que "mirar el concepto de ciudad como totalidad y de la posibilidad de acercarnos a la compresión de esta totalidad mediante el estudio de sus diversas manifestaciones de su comportamiento" (Rossi, 1982, p. 61).

Por un lado el discurso contemporáneo del proyecto de arquitectura, paralelo al de construcción de la ciudad, afianza sus argumentos en esta deriva de sociedad del exceso, la profusión y la forma, dando en definitiva una nueva dimensión de la escala. Por otro, quedan las palabras de Aulis Blomstedt (1959) sobre la arquitectura como arte de la moderación, la reserva y la modestia: "el estilo es el resultado de una postura ética y de una elección. La elegancia sólo puede alcanzarse a través del ascetismo" (p.35). En el centro quedan numerosas arquitecturas que se relacionan dentro del soporte ciudad; todas ellas representativas de una forma de entender la realidad, de convivir 
con el medio, de interaccionar entre discursos y demandas sociales y de una síntesis entre el lugar y pensamiento (aprehendido o adquirido). La relación entre ambos modelos queda manifiesta cuando sobre elementos heredados de sociedades pretéritas se pretende intervenir con modelos contemporáneos. Ahí radica el encuentro, el límite, la frontera (diluida o redibujada). "Probablemente falte algo en la formación del arquitecto. Antaño uno tenía que ser primero artesano, trabajar como tal un cuatrimestre del primer año de la carrera..." (Utzon, 2010, p.77).

\section{Metodología: frente al prototipo digital, la maqueta del artesano}

La maqueta, como herramienta del arquitecto, es la perfecta unión entre la mano y la luz; entendiendo esta como un material más. La maqueta es el ejercicio artesanal por el que el arquitecto dimensiona el espacio proyectado gracias a la reacción de esta frente a la luz. Por ello el arquitecto artesano verá en la luz un material especial y esencial, un material del que no podrá prescindir y con el que tendrá que trabajar en paralelo. Desde su experiencia, Alberto Campo (2015) dirá:

he contado alguna vez cómo un buen amigo mío, un sapientísimo ingeniero, me recriminaba el que hiciera hacer maquetas a mis alumnos. Y argumentaba que hoy día es mucho mejor trabajar con el ordenador que tan bien permite controlar las tres dimensiones. Mi argumento, incontestable, era que nunca había visto a ningún arquitecto poner su ordenador bajo el sol para ver qué sucedía. Una maqueta, además de la citada simultaneidad de las tres dimensiones en movimiento y de la relación con el cuerpo humano, permite que al poner bajo el sol el espacio allí representado, a escala, reaccione de manera veraz. (p. 51) 

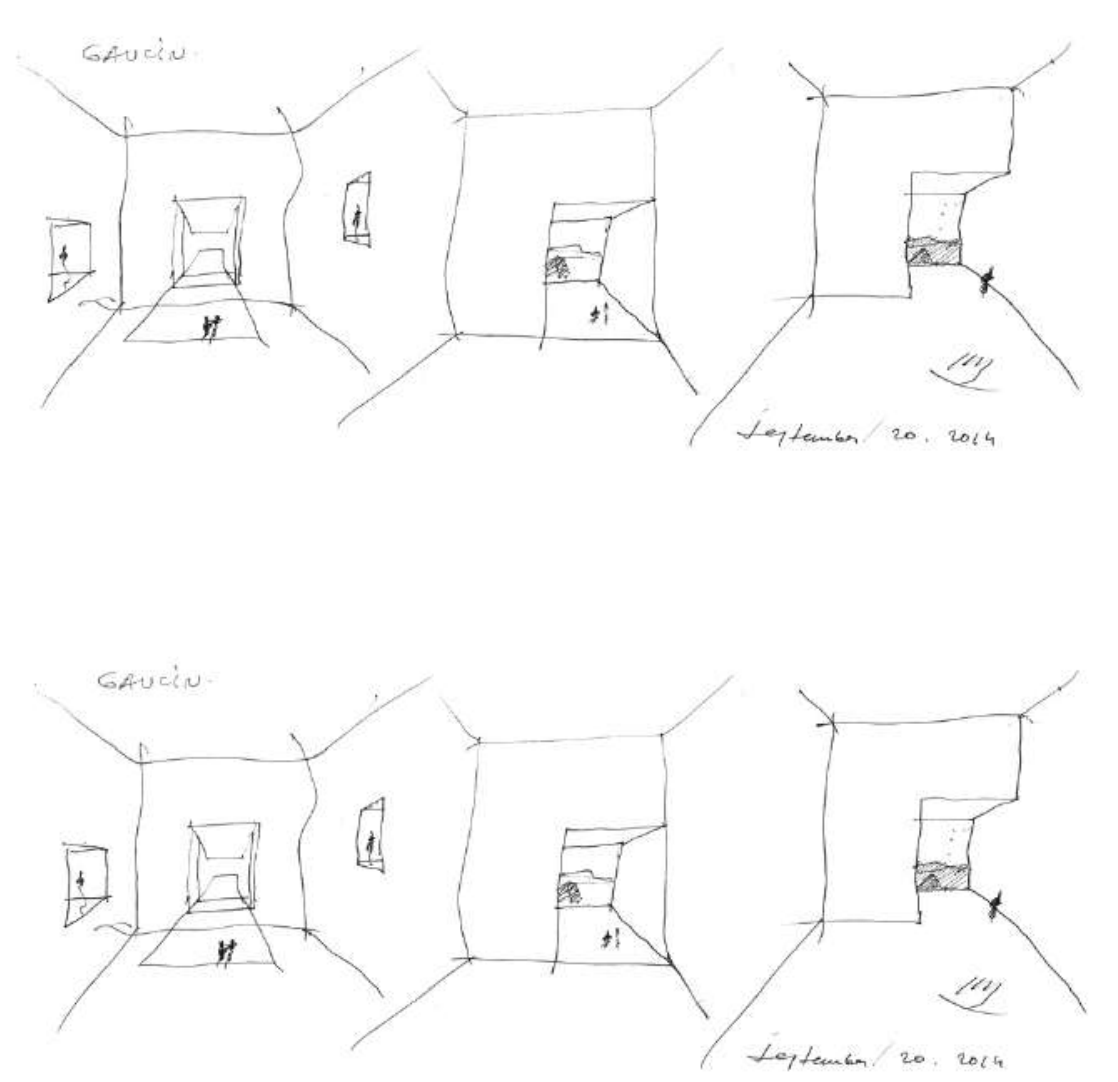

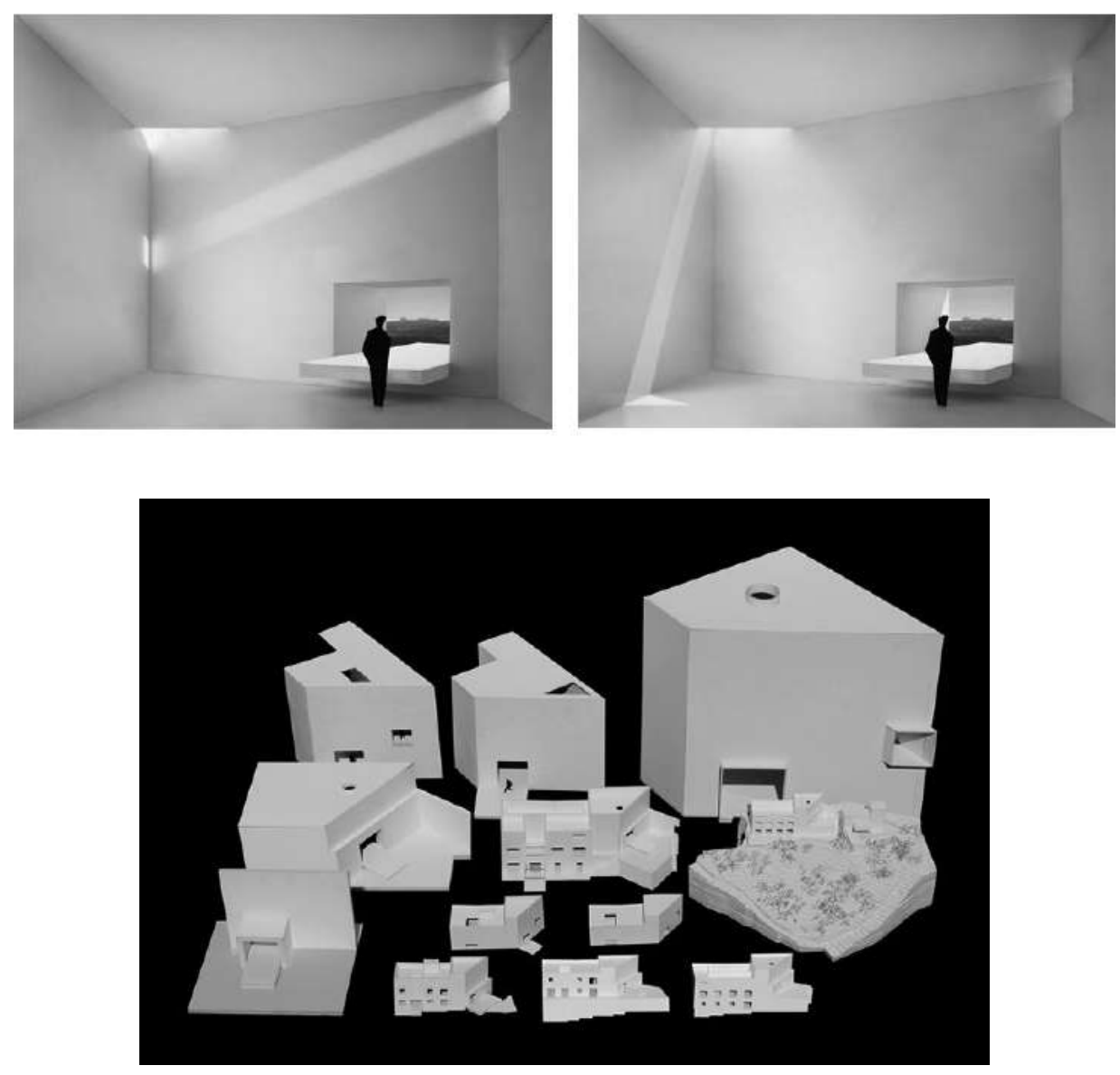

Figuras 3, 4, 5, 6. Dibujos y maquetas de Casa en Gaucín de Alberto Campo Baeza. Fuente: www.campobaeza.com 
La arquitectura basada en la lógica del artesano será la arquitectura esencial, la arquitectura que prescindirá de lo superfluo para centrarse en lo único que es propio al arquitecto: razón, materia y luz. Será la arquitectura que, partiendo del ejercicio manual que supone hacer una maqueta, estudiará los materiales que mejor representen la idea, estudiará los volúmenes bajo el Sol, estudiará las sombras y concluirá el proyecto. La maqueta será parte fundamental en el proceso creativo del proyecto arquitectónico:

decía Miguel Ángel que el dinero mejor empleado en un proyecto es el de la maqueta. La maqueta permite representar, de una forma comprensible [...]. Constituye además un instrumento de estudio y de optimización. La maqueta se puede y debe hacer paso a paso, en el estudio de Arquitectura: modelo expedito en material de fácil manipulación, apropiado para una rápida modificación, destrucción y corrección. (Siza, 2014, p. 413)

Se podría decir que la actividad del artesano es la primera actividad del hombre tras cruzar el umbral del abandono de las necesidades básicas. Para el artesano, esa primera arquitectura sería la cabaña. "Para Thoreau, para Emerson y para Hawthorne, la pequeña cabaña de los bosques equivalía a reducir a su esencia la gran tradición utópica de la primera morada" (Rykwer, 1999, p. 17). Es, por tanto, la actividad frontera. La arquitectura debe haber tenido su origen simple en el esfuerzo primitivo de la humanidad por lograr una protección contra las inclemencias del tiempo, las bestias salvajes y los enemigos humanos. (Fletcher, 1964). Es la actividad que configurará las capacidades del hombre.

Cada vez más, el trabajo de quienes se dedican a esclarecer los orígenes humanos ofrece indicios muy claros de que, desde el principio, la mano homínida y su creciente repertorio de movimientos formaban parte de lo que estaba ocurriendo en la evolución del comportamiento, la cultura y el conocimiento. Sin embargo, lo que parece más probable es que el cerebro elevara la destreza de la mano a medida que la mano iba inscribiendo en el cerebro sus incipientes complejidades sensoriales y motoras, y sus nuevas posibilidades. (Wilson, 2002, p. 291) 
El ejercicio que en arquitectura tendrá la capacidad de generar una relación directa entre mano y materia será, por tanto, la maqueta.

La educación del tacto, tiene como finalidad hacer aprender al alumno el valor de lo háptico, de las texturas, de los materiales, de su luminosidad entendida como relación entre luz y textura. Dentro del apartado táctil cabría hablar de los materiales cuya superficie es un interior continuo que emerge y aquellos en los que la superficie es un acabado, ya sea pegado, lijado, barnizado, etc. (Aparicio, 2008, p. 11)

A este respecto resulta muy iluminadora la experiencia háptica de Utzon cuando con sus manos participa en la construcción de la casa. Es muy interesante el debate abierto entre lo analógico y lo digital. La maqueta material frente la maqueta virtual. No cabe duda de que las capacidades de representación que ofrecen los nuevos software para diseño gráfico abren un amplio espectro de posibilidades. Todo ello será muy positivo para desarrollar ideas, representarlas y hacerlas inteligibles para no iniciados. Pero hay una característica en la que toda virtualidad queda en entredicho: la ausencia de una experiencia real con la materia y con el espacio. Un cuerpo material se podrá poner bajo el Sol; experimentar los espacios de luz y sombra; observar y analizar el espacio real generado... En definitiva, la materia permite una experiencia directa de los espacios en luz y en sombra, del tacto, de la calidad de sus terminaciones, del detalle entre otros.

La maqueta es un objeto de reflexión sobre el que se dan una serie de propiedades dialécticas, no dicotómicas.

El hombre no tiene empeño alguno por estar en el mundo. En lo que tiene empeño es en estar bien. Sólo esto le parece necesario y todo lo demás es necesidad sólo en la medida en que haga posible el bienestar. Por tanto para el hombre sólo es necesario lo objetivamente superfluo. (Ortega y Gasset, 2005, p. 34) 


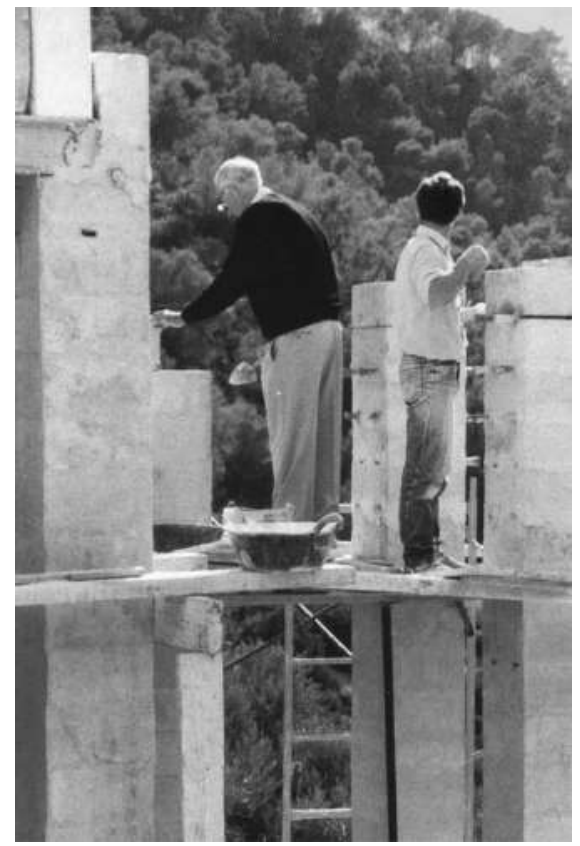

Figura 7. Utzon construyendo Can Feliz. Fuente: www.elcroquis.es.

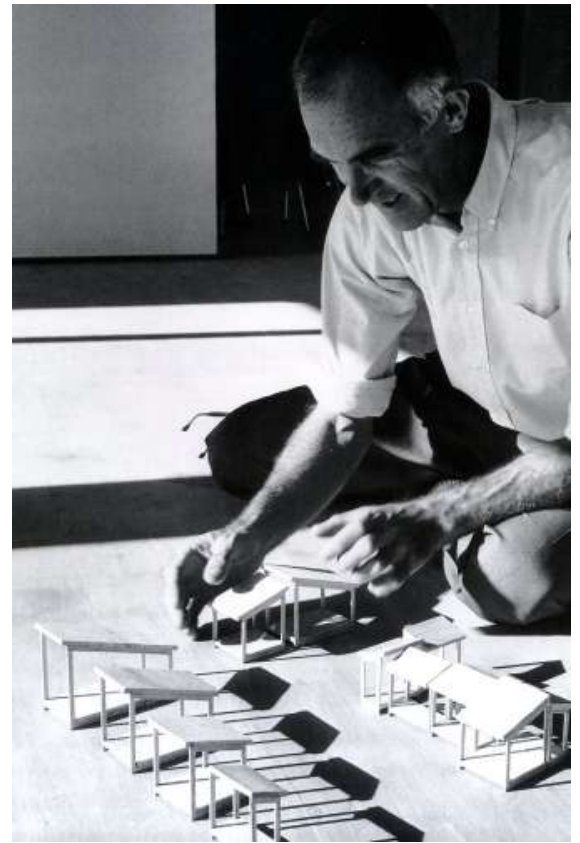

Figura 8. Utzon trabajando con las maquetas y la luz. Fuente: www.arquitecturaviva.com. 


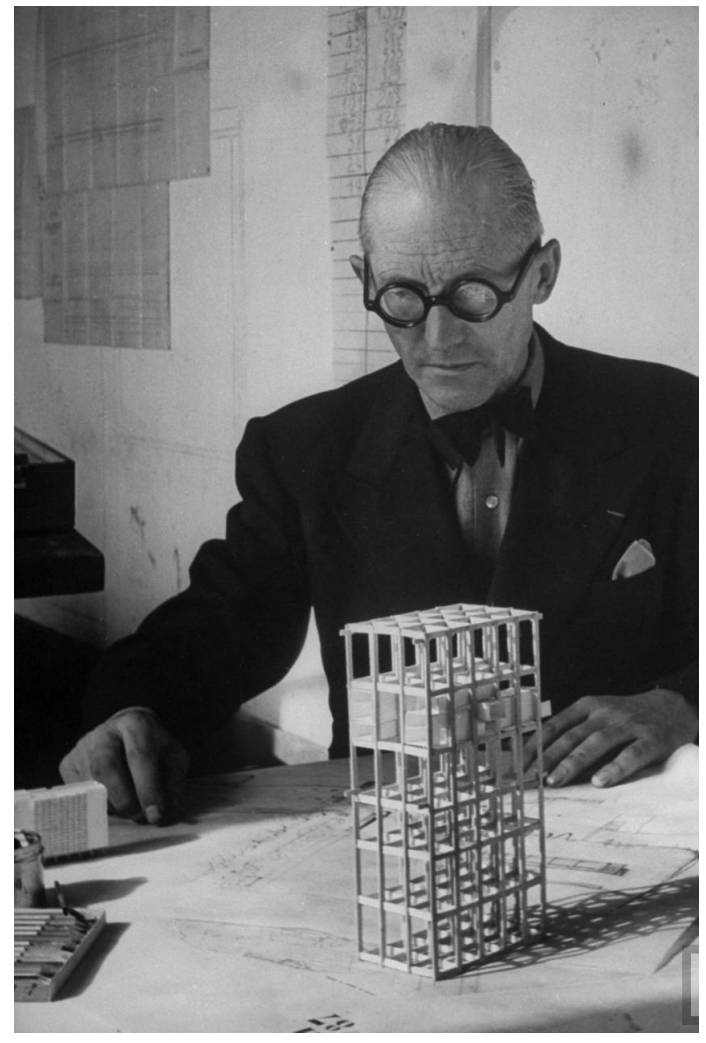

Figura 9. Le Corbusier trabajando con el dibujo y la maqueta. Fuente: www.arquitecturaviva.com. 


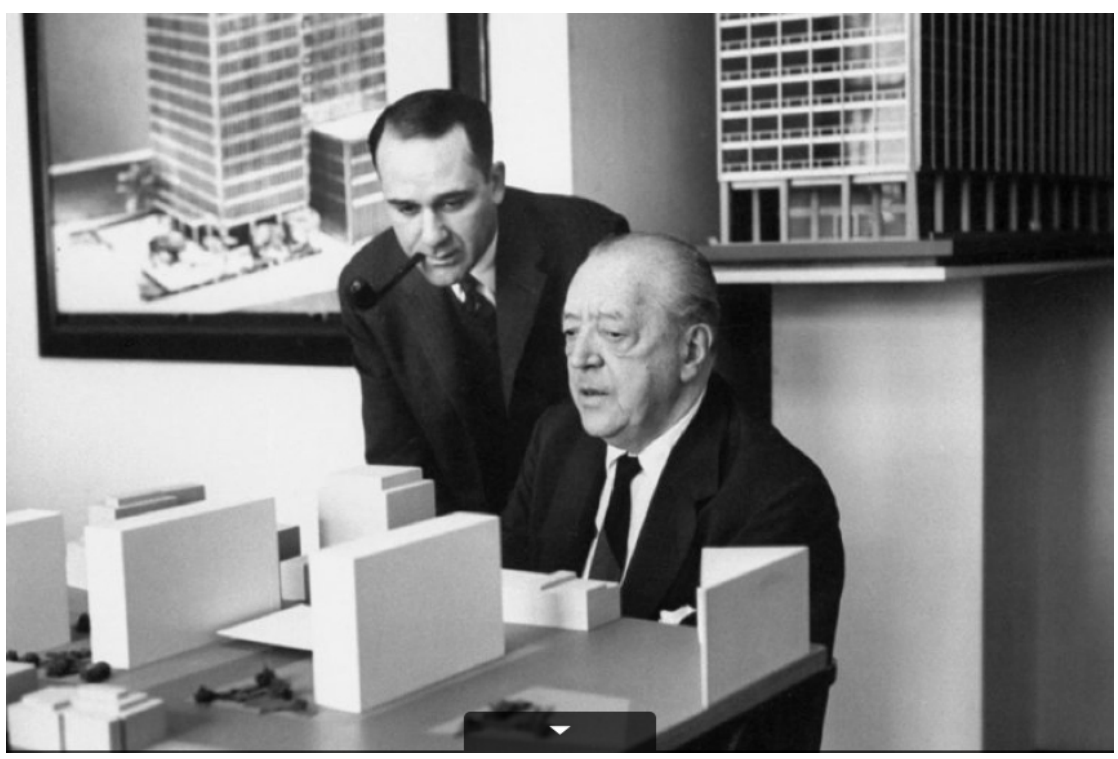

Figura 10. Mies y Herbert Greenwald trabajando con maquetas. Fuente: www.arquitecturaviva.com.

Con la maqueta o el prototipo, el artesano ve la luz porque detecta la sombra; modifica la delimitación de un vacío porque tiene la capacidad de detectar la materia. El objeto del artesano hará dialogar todos los elementos que convergen en él. Será el tiempo dedicado a la elaboración y a la reflexión llevada en paralelo el mejor crisol dialéctico de todos los elementos. Este ejercicio pondrá en crisis los procedimientos fabriles dado que cada pieza, cada corte en el material, cada plano será objeto de una reflexión. El resultado del trabajo del artesano no será lo necesario, pero sí lo primero surgido de este ejercicio intelectual. 
La inmediatez de la máquina desensibiliza al hombre. Todo proceso creativo y de creación tiene un tiempo. La máquina o la virtualidad, quitando el tiempo en sus procesos, eliminan consigo los tiempos de reflexión y meditación paralelos. El objeto del artesano, gracias a la maduración llevada a cabo durante el ejercicio de creación, será una extensión del propio hombre que lo crea. En arquitectura el proceso es paralelo. La participación de la mano en dibujos, bocetos, maquetas, prototipos, entre otros, conseguirá hacer del tiempo un momento de maduración del proyecto arquitectónico: todo tendrá un porqué. La dinámica de depuración llevada a cabo por la implicación de la mano será garante de un resultado reflexionado, pensado, proyectado.

El artesano no busca la ambivalencia dicotómica entre la mano y la máquina sino en términos de complementariedad. De ahí el deseo insatisfecho de un artesano en una continua búsqueda por perfeccionar el desarrollo de nuevas técnicas, nuevas formas de desarrollar sus obras. Igualmente ocurrirá en arquitectura tal como subraya Mies:

ésta puede que sea la razón por la que alguna gente está convencida de que la arquitectura quedará anticuada y será reemplazada por la tecnología. Tal convicción no se fundamenta en ideas claras, sino todo lo contrario. Donde la tecnología alcanza su verdadero cumplimiento, va más allá de la arquitectura. Es cierto que la arquitectura depende de hechos, pero su verdadero campo de actividad se encuentra en el terreno de la trascendencia. Espero que entiendan que la arquitectura no tiene nada que ver con la invención de formas. No es un campo de juegos para niños, jóvenes o mayores. La arquitectura es el verdadero campo de batalla del espíritu. La arquitectura escribió la historia de las épocas y dio a éstas sus nombres. La arquitectura depende de su tiempo. Es la cristalización de su estructura interna, el lento despliegue de su forma. Ésta es la razón por la que la tecnología y la arquitectura están tan estrechamente relacionadas. Nuestra verdadera esperanza es que crezcan juntas, que algún día una sea la expresión de la otra. Sólo entonces tendremos una arquitectura digna de su nombre: una arquitectura como un símbolo verdadero de nuestro tiempo. (Como se citó en Puente, 2006, p. 26) 
¿Es, por tanto, la máquina una herramienta de oposición al artesano? Si hacemos análisis a lo largo de la historia puede parecer que la máquina comenzó siendo un apoyo al trabajo del artesano para acabar sustituyéndolo. Si entendemos el trabajo de este como el trabajo repetido y alienado podríamos asemejarlo. Es más, hoy en día, con el desarrollo de la microelectrónica o la robótica aplicada podríamos hablar de una búsqueda intensa e incansable por la sustitución del hombre por la máquina. Este antiguo debate no tendría ninguna razón de ser en arquitectura. Es cierto que han sido numerosos los ensayos que han intentado hacer del ejercicio proyectual una suma de causalidades o una matriz de datos de resultados babélicos:

el camino para lograr una arquitectura diversa y humana pasa por entender la inspiración que existe detrás de cada expresión humana, por trabajar en base a nuestras manos, ojos, pies, estómago, en base a nuestros movimientos y no en razón a normas estáticas y reglas creadas estadísticamente. (Utzon, 1948, p. 32)

Estos ejercicios de sistematización comienzan en un intento de hacer de la mano una máquina para acabar inversamente haciendo de la máquina una mano. Es decir, son ejercicios proyectuales en busca de una sofisticación de laboratorio. La sabiduría del artesano, será saber qué corresponde a la mano y qué a la máquina y hacer converger la maqueta en una mano.

Discusión: frente a la asepsia del laboratorio, el taller del artesano

Zumthor subraya las dos aptitudes del arquitecto en su taller: el trabajo con las manos y la concentración. 
Cuando tenía 18 años, mi período de aprendizaje como ebanista se acercaba a su fin y me puse a construir los primeros muebles diseñados por mí. Normalmente en el taller producíamos muebles cuya forma y construcción estaba determinada por el gusto del maestro o de los clientes y que a mí no me gustaban. Tampoco me gustaba la madera que empleábamos para las mejores piezas: nogal. Para mis muebles escogí la madera blanca de fresno, y trabajé cada pieza de manera que tuvieran un buen aspecto desde cualquier lado; estaban acabadas con idéntico cuidado y con el mismo material por delante y por detrás. Rehusé la costumbre que tenían los ebanistas de construir la parte trasera de los muebles de una forma más económica y con menos aplicación, pues, al fin y al cabo, esa parte no la ve nadie. Por fin podía redondear un poquito los cantos de mis muebles sin que nadie me corrigiera. Con suavidad y rapidez pasaba la garlopa sobre los cantos de las piezas de madera ya montadas con el fin de quitarles el filo cortante que pudiera estorbar y conservar la elegancia de la línea fina y precisa. Apenas tocaba con la garlopa los rincones donde convergían tres cantos de las piezas del mueble. Construía la puerta de los muebles pequeños en el marco frontal, sirviéndome minúsculas juntas, de manera que cerrase con toda precisión mediante un resorte de rozamiento y un sonido neumático ligeramente perceptible. Me sentía bien con aquel trabajo. Realizar formas precisas y sólidas encajaduras me colocaba en un estado de concentración, y los nuevos muebles ya acabados difundían un frescor especial a mi alrededor. (Zumthor, 2014, p. 42)

Dice Sennett que el taller es el hogar del artesano. Posiblemente estas palabras las pronunció en un sentido figurado, aunque la historia nos muestra cómo esta afirmación podía ser perfectamente literal: taller o casa donde se hace la vida, lugar pequeño. Hay un cuadro de Rembrandt en el Louvre que muestra perfectamente esta idea. La obra tiene un doble título: La Sagrada Familia o Las herramientas del carpintero. Lo cierto es que observar el cuadro desde un título $\mathrm{u}$ otro muestra dos realidades completamente diferentes, pero no ajenas al entorno en el que Rembrandt ubica la escena. Si el cuadro relata un episodio de Los Evangelios resulta lógico que en el contexto de la carpintería de San José, María amamante a Jesús. Pero centrémonos en la otra posibilidad. La escena de género en la que una mujer amamanta un niño en una carpintería rodeada de herramientas, entretanto un hombre pensativo mira la obra que está haciendo. Esta escena muestra perfectamente el lugar de trabajo de un artesano. 


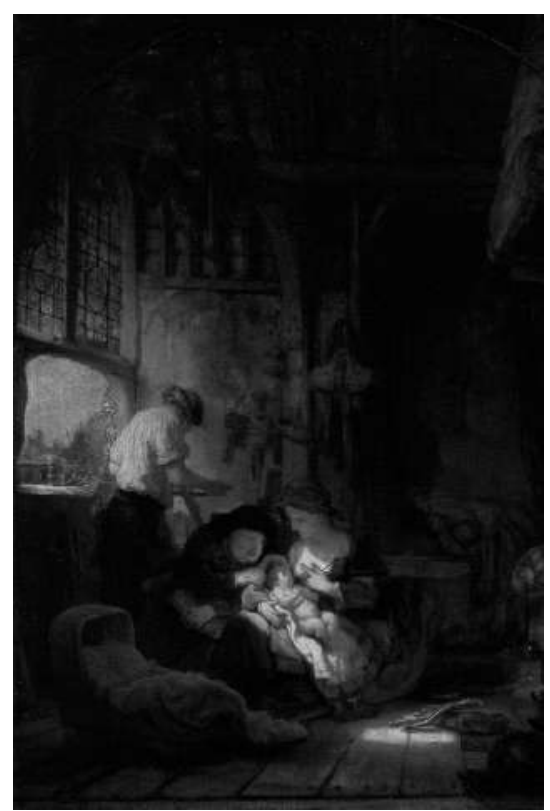

Figura 11. La Sagrada Familia o Las herramientas del carpintero de Rembrandt. Fuente: www.louvre.fr.

Según el DRAE las tres acepciones de taller hacen referencia a ese espacio pequeño: "lugar en que se trabaja una obra de manos"; "escuela o seminario de ciencias o de artes"; "conjunto de colaboradores de un maestro". Con la primera, introducimos el valor de la acción manual frente a la máquina; con la segunda, el lugar de aprendizaje; y con la tercera, el ámbito en el que se crea una relación maestro-discípulo. La confluencia de estos tres objetivos (trabajar manualmente, aprender y enseñar), será lo que denominemos como un lugar de experimentación. 
El taller era el lugar contrario al templo o, mejor dicho, el opuesto al eremitorio. Esta concepción originaria del monacato, mostraba al monje cómo para llevar una vida equilibrada debía compaginar la vida eremítica con la artesanal. De ahí surge la convivencia en la celda de un espacio reservado para la oración silenciosa y otro para el trabajo manual (que normalmente sería la carpintería). La ambivalencia era clara: estar apegado al cielo con la oración y a la tierra con el trabajo artesanal. En el monacato, el taller será visto como un lugar que obligará al monje a salir del ámbito de la oración personal sin llegar a dispersarle al ser también un ámbito de reflexión.

Posteriormente las órdenes mendicantes, a partir del siglo XIII, harán una revisión de ese paradigma y no solamente fomentarán el trabajo manual sino que lo obligarán: "y yo trabajaba con mis manos, y quiero trabajar; y quiero firmemente que todos los otros hermanos trabajen en trabajo que conviene al decoro" (San Francisco de Asís, Test. 20). Esta nueva visión del trabajo manual eliminará de los nuevos conventos (frente a los antiguos monasterios) los espacios reservados al trabajo manual dado que saldrán a la calle a buscar su sustento en un ejercicio de inclusión social.

El taller podría considerarse el ámbito donde el artesano está físicamente, pero no mentalmente. Aunque, si no está aquí con la cabeza, ¿dónde se encuentra? Dice Zweig (2011) que "la contestación es muy simple. Está en su obra. Mientras crea, no está en su mundo, en nuestro mundo, sino en el mundo de su obra, y por esto mismo es incapaz de observarse a sí mismo" (p. 20).

Frente al individualismo relativista de la sociedad posmoderna contemporánea, centrada en el hedonismo propio de etapas pueriles, la lógica del artesano apostará por la madurez de un contexto colaborativo. Frente al yo, se apostará por un nosotros. Frente a la idea individual planteará el trabajo en equipo: "la diferencia es básica; el individualismo, la atomización individualista implica, 
la negación de los valores humanos colectivos y, como consecuencia el olvido de las obligaciones que esos valores entrañan. Pura irresponsabilidad, en definitiva" (Vicens, 2012, p. 78).

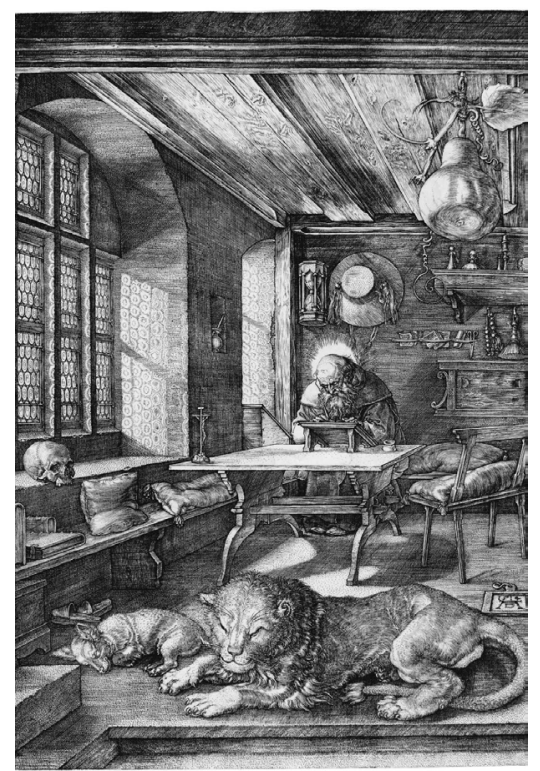

Figura 12. San Jerónimo en su celda de Durero, 1514. Fuente: www.artehistoria.com

Para un arquitecto su taller es su estudio. Es su pustinia' ${ }^{1}$ Es un lugar de estudio, de lectura, de investigación, de trabajo personal y colectivo, es el lugar más privado y personal. Allí tiene proyectos en curso, proyectos futuros, proyectos que pudieron ser y fueron y otros que durmieron la paz de los justos. Libros, maquetas, un trozo de un material de una obra, vino, fotografías impresas o

${ }^{1}$ La palabra rusa pustyn designa a un tipo de pequeña habitación o reducido habitáculo escasamente amueblado destinado a la oración y al ayuno, buscando la mínima dispersión posible. 
simplemente una hoja de algo que le gustó y está allí simplemente porque aún no se ha tirado. Un arquitecto se proyecta a sí mismo en su estudio. Parafraseando el refrán "dime con quién andas y te diré quién eres", podríamos decir "dime cómo es tu estudio y te diré qué arquitecto eres".

Entrar a un estudio es un ritual. El olor a libros, materiales, colas, madera o simplemente café de la larga noche de trabajo. En un estudio se trabaja, se celebra, se vive y se duerme. ¿Qué sería de un artesano sin su taller o de un arquitecto sin su estudio? La obra de un arquitecto tiene una relación directa con este espacio de trabajo. El arquitecto busca la luz en su estudio, al igual que la busca y la encuentra en su obra. Un arquitecto hace de su estudio un lugar de reflexión paralelamente a lo que ocurrirá con su obra. Un arquitecto se proyecta en su estudio lo mismo que lo hace en su obra. El estudio de un arquitecto, por tanto, será una obra más; un proyecto en continuo desarrollo:

todo está relacionado con nosotros mismos. El entorno nos influye mediante su dimensión, luz, sombra, color, etc. Nuestra condición es completamente dependiente del hecho de vivir en la ciudad o en el campo, de si nos encontramos en una habitación grande o pequeña. (Utzon, 1948, p.141)

En el estudio (taller) de un arquitecto se dan diferentes encuentros:

1. Un encuentro personal consigo mismo: lugar de reflexión. Es el lugar de estudio, de análisis de otros proyectos, de pensar diferentes soluciones y detalles constructivos, de investigar nuevos materiales; sobre todo, el lugar donde acontece la génesis de nuevos proyectos. Si hay musas, estas tienen que vivir en el estudio de un arquitecto. Será un lugar de silencio, pero también de continuo diálogo, de trabajo, pero también de reposo meditativo.

2. Encuentro con la alteridad: lugar de transmisión y recepción. Se trabaja en equipo, se piensa en equipo, se proyecta en equipo. La reciprocidad del trabajo en el taller hace de este lugar un espacio de aprendizaje colaborativo. Es bueno 
que los arquitectos empecemos a colaborar en estudios desde edades tempranas, siendo estudiantes. Lo que se aprende en el taller (estudio) no se aprende en clase.

3. Encuentro con el papel en blanco: lugar de proyección. Si cabe el encuentro más íntimo para un artesano es el que se produce con su obra. El silencio que envuelve los primeros golpes sobre la piedra para el escultor, los primeros cepillados que el ebanista da al bloque de madera o el momento en el que se plasman los primeros trazos en el blanco lienzo. Son encuentros personales. El papel en blanco para el arquitecto es el ejercicio fundante que continuamente le hará enfrentarse con su propia realidad. Es en esta duda constante, y en el silencio táctil de los pensamientos que con líneas creadoras se construyen en nuestra mente y en nuestra mano, donde expresamos todo lo que tenemos de más profundo para decir al mundo y a la arquitectura a través de un proyecto.

\section{Conclusiones}

Trabajar con la maqueta es hacer un ejercicio de búsqueda de lo esencial, un ejercicio que une el trabajo manual y material del arquitecto. En un contexto en el que se valora la imagen y lo superficial frente a la profundidad y dedicación de lo artesanal; el trabajo con maquetas es la referencia que aglutina todo el contexto de un arquitecto y define el lugar de trabajo, el taller como ámbito donde se desarrolla su realidad más personal. Desvelar (romper el velo) para entrar en el sancta sanctorum de las ideas, trabajo, biblioteca... es el acto más generoso que un arquitecto puede hacer. Existe un límite en el que el taller de un artesano deja de serlo para ser una fábrica, al igual que ocurre cuando se deja de trabajar con maquetas para ensayar únicamente de forma digital. Esa delgada línea es transgredida cuando el artesano pasa de hacer con sus propias manos a controlar la producción, cuando deja de utilizar materiales analógicos para únicamente ver construcciones digitales. Así, el taller del artesano será al estudio del arquitecto lo que una fábrica es a una gigantesca oficina de arquitectura. Al respecto, dice Ortega y Gasset (2005): 
el artesano tiene que aprender en largo aprendizaje —es época de maestros y aprendices— técnicas que ya están elaboradas y vienen de una insondable tradición. El artesano va inspirado por la norma de encajarse en esa tradición como tal: está abierto al pasado y no abierto a posibles novedades. Sigue el uso constituido. Se producen, sin embargo, modificaciones, mejoras, en virtud de un desplazamiento continuo y por lo mismo imperceptible; modificaciones, mejoras, que se presentan con el carácter no de innovaciones sustantivas, sino, más bien, como variaciones de estilo en las destrezas. Estos estilos de tal o cual maestro se transmiten en forma de escuelas; por tanto, con el carácter formal de tradición. (p. 81)

El artesano hará con las manos y el arquitecto artesano, con una maqueta, contendrá una idea en la mano.

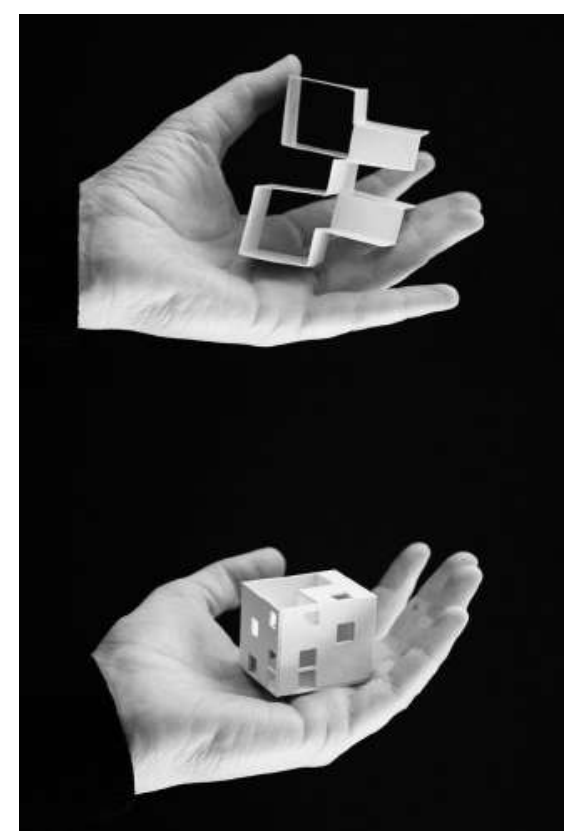

Figura 13. Maquetas de proyectos de Alberto Campo Baeza. Fuente: www.campobaeza.com. 


\section{Referencias}

Aparicio, J.M. (2008). Construir con la razón y los sentidos. Buenos Aires, Argentina: Nobuko.

Campo, A. (2015). Poética architectonica. Madrid, España: Editorial Mairea.

Capel, H. (2002). La morfología de las ciudades. Barcelona: Ediciones del Serbal.

de Asís, F. (Sin fecha). Testamento. Recuperado de http://www.franciscanos. org/esfa/teste.html.

Fletcher, B. (1964). A history of Architecture, being a comparative view of the historical styles. London, England: Franklin Classics.

Gropius, W. (1919). Programa de la Bauhaus de Weimar.

Kahn, L.I. (2003). Espacio, forma, uso. Madrid, España: El Croquis Editorial.

Marinetti, F. (2015). Primer manifiesto del futurismo. Recuperado de https:// salesianosctg.wordpress.com/2015/10/24/primer-manifiesto-delfuturismo-1909/.

Morin, E. (2006). El método. Madrid, España: Cátedra.

Ortega y Gasset, J. (2005). Meditación de la técnica y otros ensayos sobre ciencia y filosofía. Madrid, España: Alianza.

Pallasmaa, J. (2015). Una arquitectura de la humildad. Barcelona, España: Fundación Caja de Arquitectos.

Pallasmaa, J. (2015). De la Utopía al Monumento, en Cuaro Cuadernos. Apuntes de Arquitectura y Patrimonio. 
Puente, M. (2006). Conversaciones con Mies van der Rohe. Barcelona, España: Gustavo Gili.

Ricoeur, P. (1965). History and Truth. Evanston, USA: Northwestern University Press.

Rossi, A. (1982). La arquitectura de la ciudad. Barcelona, España: Gustavo Gili.

Rykwer, J. (1999). La casa de Adán en el paraíso. Barcelona, España: Gustavo Gili.

Siza, Á. (2014). Textos. Madrid, España: Adaba Editores.

Utzon, J. (1948). La esencia de la arquitectura. Barcelona, España: Gustavo Gili.

Utzon, J. (2010). Conversaciones y otros escritos. Barcelona, España: Gustavo Gili.

Vicens, I. (2012). Dicho y hecho. Buenos Aires, Argentina: Nobuko.

Wilson, F. (2002). La mano. De cómo su uso configura el cerebro, el lenguaje y la cultura humana. Barcelona, España: Matemas.

Zumthor, P. (2014). Pensar la arquitectura. Barcelona, España: Gustavo Gili.

Zweig, S. (2011). El misterio de la creación artística. Madrid, España: Sequitur.

Como citar: Millán-Millán, P.M. (2019). Una maqueta en una mano: hacia la búsqueda de lo esencial. Revista KEPES, 16 (19), 95-121. DOI: 10.17151/kepes.2019.16.19.5 